\title{
Leibniz on substance in the Discourse on Metaphysics ${ }^{1}$ \\ Gonzalo Rodriguez-Pereyra \\ Oriel College, Oxford
}

1. In the Discourse on Metaphysics Leibniz put forward his famous complete-concept definition of substance. Sometimes this definition is glossed as stating that a substance is an entity with a concept so complete that it contains all its predicates, and it is thought that it follows directly from Leibniz's theory of truth. ${ }^{2}$ Now, an adequate definition of substance should not apply to accidents. But, as I shall point out, if Leibniz's theory of truth is correct then an accident is an entity with a concept so complete that it contains all its predicates. The aim of this paper is to clarify Leibniz's notion of substance in the Discourse with a view to explaining how that definition successfully distinguishes between substances and accidents.

The plan of the paper is as follows. In section 2 I shall present the relevant passage from the Discourse and discuss both the merely nominal definition of substance with which Leibniz begins the passage and his theory of truth. In section 3 I shall explain why on Leibniz's theory of truth an accident is an entity with a concept so complete that it contains all its predicates. This means that Leibniz's definition is incorrect if it defines a substance as an entity with a concept so complete that it contains all its predicates. In section 4 I shall argue that appealing to Leibniz's Nominalism is no way of saving the definition of substance. In sections 5 and 6 I shall explain what Leibniz's complete-concept definition of substance really amounts to. The main task of these sections is to explain in what sense accidents have complete concepts that include all their predicates and in what sense they do not. In section 7 I shall consider an important note Leibniz wrote at the

\footnotetext{
${ }^{1}$ Thanks for discussion to Maria Rosa Antognazza, Donald Baxter, Martha Brandt Bolton, István Bodnár, Paolo Crivelli, Katalin Farkas, Robert Garcia, Michael Griffin, Ghislain Guigon, John Heil, Ferenc Huoranszki, Paul Lodge, Don Rutherford, Pedro Santos, Jeff Snapper, Ezequiel Zerbudis, and audiences in Budapest, Buenos Aires, Geneva, and York.

2 Jolley 2005: 48-9, Broad 1972: 2, Russell 1937: 9-11; what Wilson says (1989: 89) also suggests this kind of picture. Others, like Rutherford, reject this view (Rutherford 1988 and 1995). I side with Rutherford on this point, but my interpretation is different from his.
} 
margin of one of his letters to Arnauld and I shall elucidate it on the basis of my argument in section 6 . In section 8 I shall consider some texts, previous to the Discourse, where Leibniz says that only substances have complete concepts that include all their predicates. I shall argue that the Discourse can then be seen as representing an evolution in Leibniz's thought on substance in the mid-1680s. In section 9 I shall explain why, although Leibniz's definition successfully distinguishes substances from accidents, it does not distinguish substances from substantial forms. Section 10 is a short conclusion.

2. In Section 8 of the Discourse on Metaphysics Leibniz says the following:

It is indeed true that when several predicates are attributed to the same subject and this subject is not attributed to any other, it is called an individual substance; but this is not sufficient, and such an explanation is merely nominal. It must therefore be considered what it is to be attributed truly to a certain subject.

Now it is evident that all true predication has some ground in the nature of things, and when a proposition is not identical, that is, when the predicate is not explicitly contained in the subject, it must be contained in it virtually, and this is what the philosophers call in-esse, when they say that the predicate is in the subject. Thus the term of the subject must always include that of the predicate, so that he who understood perfectly the notion of the subject would also judge that the predicate belongs to it.

This being so, we can say that the nature of an individual substance or of a complete being is to have a notion so complete that it should be sufficient to contain and to allow deduction from it of all the predicates of the subject to which this notion is attributed. Instead, the accident is a being whose notion does not include everything that can be attributed to the subject to which this notion is attributed. Thus, the quality of King that belongs to Alexander the Great, taken in abstraction from the subject, is not sufficiently determinate for one individual, and 
does not include the other qualities of the same subject, nor does it include everything that the notion of this prince contains... (A VI.iv: 1540). ${ }^{3}$

Here Leibniz starts with a preliminary definition of substance that has Aristotelian resonances: a substance is that subject which, although many predicates are truly attributed to it, it is not attributed to any other subject. Another way of putting this is that a substance is that subject which, although many predicates are predicated of it, it is not predicated of any other subject. Note that this is compatible with there being subjects of predication other than substances. Such subjects other than substances would be subjects of attribution or predication that are attributed to, or predicated of, other subjects. Although Leibniz does not mention this possibility explicitly, I think it is not implausible, given the Aristotelian resonances of the definition and what Leibniz is going to say later, that at the beginning of the passage Leibniz is presupposing a distinction between substance and accident in precisely those terms: several things are predicated of both substances and accidents, but while a substance is predicated of no other subject, an accident is predicated of other subjects. ${ }^{4}$

It is also important to note that, in a sense, Leibniz's initial definition of substance does not have a substance as an ultimate subject of predication. An ultimate subject of predication in this sense is a subject of predication that is not predicated of any subject. But Leibniz says that a substance is not attributed to, or predicated of, any other subject. This suggests that for Leibniz a substance can be predicated of itself and so, in this sense, it is not an ultimate subject of predication. Indeed there are texts where Leibniz says that a substance is attributed to or predicated of itself: 'But the concept of a subsistent thing, for instance of this fire, is such that it includes all the attributes that can be said of that same thing of which itself [i.e. the subsistent thing - GR-P] can be said', ${ }^{5}$ or 'Furthermore, a singular substance is that which cannot be said of another. Or if a singular substance is

\footnotetext{
${ }^{3}$ All translations of Leibniz's passages are mine.

${ }^{4}$ Leibniz allows for accidents as subjects of predication in De mundo praesenti (A VI.iv: 1506).

5 'Conceptus autem subsistentis, nempe hujus ignis, est qui omnia illa attributa includit, quae de eodem dici possunt, de quo ipsum dici potest' (A VI.iv: 306).
} 
said of something, it is said of itself'. Since the concept of a certain fire includes all that can be said of that fire, the former passage implies that the fire can be said of itself. ${ }^{6}$

This might seem a trivial and minor point, but we shall see later that this is one of the keys to understanding Leibniz's conception of substance in the Discourse on Metaphysics. It might seem that this introduces a non-Aristotelian element into Leibniz's definition, since Aristotle famously said that substance is 'that which is neither said of nor in a subject' (Categories 5, 2a12-13), thereby seeming to exclude the possibility that a subject be predicated of itself. But Aristotle does allow for the possibility of a subject to be predicated of itself, since in the Prior Analytics, for instance, he says that individuals like Cleon and Callias cannot be predicated of anything else truly and universally. ${ }^{7}$ In any case, we shall see later that for Leibniz the sense in which a substance is predicated of or attributed to itself is that its concept is attributed to it.

Leibniz says that this Aristotelian explanation of substance is insufficient and merely nominal. Leibniz usually speaks of definitions being nominal. ${ }^{8}$ Although in this passage he speaks of a nominal explanation, since what he is calling nominal has the aspect of a definition, it is plausible to think that Leibniz means what he usually means when he speaks of nominal definitions. For Leibniz nominal definitions contain only marks that would enable one to distinguish the thing defined from other things, ${ }^{9}$ but they do not establish that the thing defined is possible. Thus as long as we have only a nominal definition we do not know whether the definition contains a contradiction. ${ }^{10}$ Real definitions, on the contrary, establish the possibility of the thing defined. ${ }^{11}$

\footnotetext{
${ }^{6}$ Admittedly, there are texts where Leibniz calls substances ultimate subjects (Leibniz 1992: 155). But calling them ultimate subjects does not mean that he thought of them as ultimate subjects in the strict sense of the word. More importantly, those texts, whatever their correct interpretation, do not invalidate the claim that in the Discourse and associated texts Leibniz does not seem to have thought of substance as an ultimate subject in the strict sense of the word.

${ }^{7}$ Prior Analytics 1.27, 43a25. The interpretation of this text is a delicate matter, but Barnes interprets it in this way (Barnes 2003: 325-27).

${ }^{8}$ See A VI.iv: 589, 1568.

${ }^{9}$ See A Vl.iv: 589.

${ }^{10}$ See A VI.iv: 1568.

${ }^{11}$ See A VI.iv: 1617. Interestingly, Leibniz's claim that the Aristotelian definition of substance is insufficient finds a precedent in Aristotle himself: 'We have now outlined the nature of substance, showing that it is that which is not predicated of a stratum, but of which all else is predicated. But we must not merely state the
} 
At the end of the first paragraph of the passage from the Discourse quoted above Leibniz suggests that to find a real definition of substance one must consider what it is to be truly attributed to a subject. Thus, although he does not say it explicitly, Leibniz suggests that the idea of true predication or attribution might conceal a contradiction or impossibility. Based on his considerations concerning what it is to be truly attributed to, or predicated of, a subject, Leibniz produces a different definition of a substance. Unfortunately he does not explain why this new definition establishes the possibility of substances. $^{12}$

Leibniz goes on to consider what it is to be truly attributed to, or predicated of, a subject. He says that, given that all true predication has a basis in the nature of things, the subject term always contains the predicate term. This is his famous theory of truth which, in other texts, he puts in terms of concepts: the concept of the subject always contains the concept of the predicate. This is why this theory is sometimes called the Concept Containment Theory of Truth. But sometimes Leibniz speaks simply of the subject containing the predicate. ${ }^{13}$ Although in the Discourse on Metaphysics Leibniz initially speaks of the subject containing the predicate, the reference to notions or concepts is present there, since he says that because the subject always contains the predicate, 'he who understood perfectly the notion of the subject would also judge that the predicate belongs to it' (my emphasis), and then he goes on to speak of the notion of the subject containing the predicates of the subject. I do not want to make much of this since I think Leibniz took all these different formulations of his theory of truth as equivalent. ${ }^{14}$ But I shall use the version of the theory that according to which the concept of the subject always contains the predicate.

matter thus; for this is not enough. The statement itself is obscure, and further, on this view, matter becomes substance' (Metaphysics 1029a7-10).

${ }^{12}$ Joseph suggests that the nominal character of the definition of substance is due to the fact that it is not clear that the two features of being that in which several predicates inhere and of non-inhering in any other subject, are compatible (1949: 71). But what Leibniz does in the second paragraph of our passage suggests that the possible incompatibility of those two characters is not what worried him, since he simply concentrates on explaining what true predication consists in and does not refer at all to the fact that a substance can be predicated of itself.

${ }^{13}$ A VI.iv: 1644.

${ }^{14}$ A VI.iv: 551, G.ii.43, 56. 
Thus, according to Leibniz, for a predicate to be truly attributed to a subject is for it to be included in the concept of the subject. His theory is intended to be perfectly general and it is intended to apply to all propositions whatever their subject matter. Indeed it would be very odd if for Leibniz only propositions about some entities were such that the concept of the subject contains the predicate. For then it would hardly be the case that 'all true predication has some ground in the nature of things'.

It might be controversial whether Leibniz has, in any sense, clarified the notion of predication by defining it as the relation of inclusion of the predicate in the concept of the subject. But what should not be controversial is that he has not thereby put himself in a position to give a real definition of substance on the basis of that notion of predication. For he has done nothing to show that there is no contradiction or impossibility concealed in the idea of a predicate (or concept of a predicate, for that matter) being included in a concept. $^{15}$

Finally, note the conflation Leibniz makes between the Aristotelian notions of 'being said of' and 'being in' a subject. In the first paragraph Leibniz seems to be concerned with the former notion since he is concerned with attribution and predication. But when clarifying this notion in the second paragraph he says that this is what philosophers call in-esse when they say that the predicate is in the subject (Joseph notes that Leibniz ignores this Aristotelian distinction). ${ }^{16}$ What is most extraordinary is that Leibniz is implicitly attributing his theory of truth to Aristotle, something he does explicitly in other texts, for instance Notationes Generales, ${ }^{17}$ and Primary Truths. ${ }^{18}$

3. In the third paragraph of the passage from section 8 of the Discourse quoted above Leibniz appears to derive a definition of substance from his theory of truth. What he says

\footnotetext{
${ }^{15}$ At least once Leibniz defines a notion or concept as that which does not imply any contradiction or involves nothing impossible (A VI.iv: 570 ). But such a definition can only be stipulative. Thus it would not be satisfactory to claim that he has shown that there is no contradiction or impossibility involved in the idea that predicates are contained in concepts because, by definition, concepts imply no contradiction and involve no impossibility.

16 Joseph 1949: 71.

${ }^{17}$ A Vl.iv: 551.

${ }^{18}$ A VI.iv: 1644.
} 
suggests, and is often glossed as meaning, that the nature of a substance is to have a concept that is complete in the sense of including and allowing deduction of all its predicates, i.e. in the sense of including and allowing deduction of everything that is true of it. $^{19}$

Now, it is true that for Leibniz a substance has a complete concept that contains or includes all its predicates and therefore it contains or includes everything that is true of it. And that a substance has a concept that includes all its predicates follows from Leibniz's theory of truth. For according to this theory the predicate is always included in the concept of the subject. Thus the concept of the subject must contain all the predicates of the subject. Since according to Leibniz a substance is the subject of predicates, its concept must contain all of them. But being something whose concept contains all its predicates is not the definition of a substance. Indeed attributing to Leibniz such a definition of substance would be deeply problematic, as we shall now see.

For surely accidents can be subjects of predication. And that they are seems to be consistent, as I said, with the merely nominal definition of substance with which Leibniz begins the passage we are discussing. Now, if accidents are subjects of predication, given that all true predication consists in the concept of the subject containing the predicate, and that this is the reason why substances have complete concepts that contain all their predicates, then accidents should have complete concepts too. But if accidents have complete concepts that contain or include all their predicates, then having such concepts is not what defines a substance. ${ }^{20}$

Thus either Leibniz produced an extensionally incorrect definition of substance, or his definition of substance is not that of a being whose concept contains or includes all its predicates.

\footnotetext{
${ }^{19}$ From now on, for simplicity and convenience only, I shall speak of concepts including or containing predicates, without reference to allowing deduction of them. But this should not be taken to suggest that Leibniz thought of concepts as lists.

${ }^{20}$ This problem has been noted by Parkinson (1965: 125-26) and Rutherford (1988: 131, 1995: 120). Parkinson presents the problems in terms of abstractions rather than accidents and Rutherford presents it in terms of species rather than accidents. But the problem is the same as the one I am presenting in terms of accidents: Leibniz's theory of truth on its own does not seem to produce a definition that applies only to substances. I prefer to formulate the problem in terms of accidents because Leibniz's intention, in the passage I am analyzing, is to distinguish substances from accidents.
} 
4. It might be argued that Leibniz rejected the existence of accidents, and therefore Leibniz's definition of a substance is not extensionally incorrect. On this view, accidents do not exist and so they do not satisfy his definition of a substance. And, indeed, there are texts in which Leibniz seems to reject accidents, for instance the De realitate accidentium, where Leibniz argues that what appears to be talk of accidents is in fact an abbreviated way of talking about substances. ${ }^{21}$ One might then think that for Leibniz accidents are not subjects of predication, and so it is not the case that they satisfy his definition of substance. $^{22}$

But I do not think Leibniz's Nominalism, according to which accidents are not part of created reality, is playing a role in Leibniz's argument for his definition of individual substance. For although there is textual evidence for attributing Nominalism to Leibniz, as we have seen, ${ }^{23}$ Leibniz's views on the ontological status of accidents are not stable. There are texts in which Leibniz commits to a denial of their reality, and there are texts in which Leibniz commits to an affirmation of their reality (for instance, A VI.iv: 2770, G.iv.364, and G.vii.401).

It is interesting to note that in section 8 of the Discourse on Metaphysics, when he is distinguishing substances from accidents, Leibniz says that an accident is a being whose notion does not contain everything that can be attributed to the subject to which this notion is attributed. This, however, is consistent with his Nominalism. For Leibniz uses the word 'being' in a very general way, to apply to whatever is distinctly conceivable or

\footnotetext{
${ }^{21}$ A Vl.iv: 996.

${ }^{22}$ A line like this is suggested by some passages of Rutherford, who at one point claims that he has suggested that what is necessary to support the claim that possession of a complete concept is sufficient for something's being an individual substance is Leibniz's Nominalism (1995: 124). But his position on this issue is more complex than merely letting the solution to the problem of the definition of substance depend on Leibniz's Nominalism. The main thesis on which Rutherford relies is that Leibniz assigned a privileged explanatory role to concrete terms (1995: 107-10). So, as Rutherford has said to me in private correspondence, he reads Leibniz as addressing the question of how to define the notion of an individual substance, on the supposition that all the terms one has to work with are concrete.

${ }^{23}$ Rutherford 1988 and 1995 cite further evidence.
} 
possible. ${ }^{24}$ In this sense abstract things are beings, even if they do not exist in the created world.

But then Nominalism seems unable to play any role in Leibniz's argument for his definition of substance. For Leibniz is interested in the essence or nature of substance. That is why he is after a definition of substance. Such a definition should apply to no possible or conceivable being distinct from a substance. Thus whether accidents exist or not is irrelevant when it comes to distinguishing substances from accidents.

It might be claimed that that something is an entity does not guarantee that it is a subject of predication. In the philosophy of Frege, for instance, concepts are entities but they cannot be referred to. So why could not Leibniz maintain that accidents are entities but they are not subjects of predication? In that case accidents cannot satisfy the definition of substance. But there are at least three problems with this suggestion: (a) there are texts where Leibniz commits to the idea that accidents are subjects of predication (see, e.g., G.ii.247); (b) there seems to be no principled reason, in the philosophy of Leibniz, why any genuine beings should not be subjects of predication; and (c) nothing in the Discourse suggests this view.

But, in fact, there is no need to save Leibniz by attributing to him, in the Discourse on Metaphysics, the view that accidents are not existent entities or that they are not subjects of predication. For Leibniz's definition of substance in the Discourse is such that there is no reason to think that it might be satisfied by accidents, even if they exist and are genuine subjects of predication, as we shall see in the next section.

5. Leibniz does not say that the nature of a substance is to have a notion or concept that contains all its predicates. Instead he says that the nature of a substance is to have a notion or concept that contains all the predicates of the subject to which this notion is attributed. Now, the only thing of which the notion or concept of a substance is truly predicated is that substance itself. This clarifies the sense in which a substance is predicated of itself: strictly speaking, it is the concept or notion of a substance that is

\footnotetext{
${ }^{24}$ A Vl.iv: 568, 570.
} 
predicated of the substance in question. That a substance is attributed to or predicated of itself is a metonymic way of saying that the concept of a substance is attributed to or predicated of the substance in question.

And so, since a substance has a concept that contains all the predicates of the subject to which that concept is attributed, or of which it is predicated, and that subject is itself, it follows that a substance has a complete concept that contains all its predicates. ${ }^{25}$ But that a substance has a complete concept that contains all its predicates is not the definition of substance itself. The definition of substance, as I have said, is that a substance has a concept that contains all the predicates of the subject to which this notion is attributed.

What is the significance of this? That it allows Leibniz to maintain that accidents are genuine subjects of predication without making them satisfy his definition of substance. For what Leibniz says is that an 'accident is a being whose notion does not include everything that can be attributed to the subject to which this notion is attributed'. That is, the concept of an accident does not contain all the predicates of the subject to which that concept is attributed or of which it is predicated. Thus what distinguishes a substance from an accident is that the concept of the former contains everything that is true of the subject to which that concept is attributed, while the concept of the latter does not contain everything that is true of the subject to which that concept is attributed.

Thus Leibniz can have an adequate definition of substance without assuming nominalism or even positively assuming the reality of accidents.

It might be thought that if Leibniz thinks that it follows from his theory of truth that a substance has a concept that contains all the predicates of the subject to which that concept is attributed, he should think that it also follows from the theory of truth that an accident has a concept that contains all the predicates of the subject to which that concept is attributed. Therefore, it might be objected, Leibniz is not in a position to distinguish between substances and accidents.

\footnotetext{
${ }^{25}$ As we saw in section 3 , that a substance has a complete concept that contains all its predicates is also a direct consequence of the theory of truth, given that substances are subjects of predication.
} 
This point of view reveals a false representation of what Leibniz is doing in the passage under discussion. Leibniz is not simply advancing a theory of truth from which, and from which alone, he infers a definition of substance. Instead he is using a theory of truth to clarify the notion of true predication in order to render real the merely nominal Aristotelian definition of substance put forward at the beginning of our passage. According to this merely nominal definition, although several things are predicated of a substance, a substance is predicated of no other subject. This suggests that a substance is predicated of itself and only of itself. And if it is accepted that a substance is predicated only of itself then, given that true predication consists in the predicate being included in the concept of the subject, the concept of the substance will contain all the predicates of the subject to which it is attributed, and thus it will contain all its own predicates, that is, all the predicates of that substance itself. But it does not follow that an accident has a concept that contains all the predicates of the subjects to which that concept is attributed. For an accident, Leibniz thought, is attributed to subjects other than itself.

In effect since an accident is typically attributed to subjects other than itself, and these subjects are the bearers of different and sometimes incompatible predicates, the concept of an accident does not contain all the predicates of the subjects to which its concept is attributed, since otherwise such a concept would be inconsistent.

6. But note that Leibniz can, and indeed must, maintain that accidents have complete concepts that include everything that is true of them. To see this, consider the accident being king. What is its concept?

There are two possible answers. On the one hand, there is the concept king, which is a concept that is attributed to and predicated of kings. This is the concept that is attributed to both Alexander and Darius. On the other hand, there is the concept kinghood. This concept is not attributed to Alexander or Darius, or to any other man, but to an accident, namely the accident being king. The latter concept is the concept of a certain accident because it characterizes that accident. The former concept is the concept 
of a certain accident because it characterizes the subjects of that accident in virtue of those subjects having that accident.

Furthermore, the concept kinghood should be considered to be complete by Leibniz. For take the collection of all the true predications about the accident being king. In all of them a certain predicate is attributed to the accident being king (e.g. that it is an accident, that it is an accident had by powerful men, that it is an accident many men desire to have, etc.). But since the concept of the subject includes everything that is true of it, the concept kinghood must include everything that is true of the accident being king. For the concept kinghood is the concept that characterizes the accident being king.

But the concept king does not completely characterize the subjects to which it applies. For this concept is attributed to men like Alexander and Darius, but the concept king does not contain everything that is true of them since being a king does not exhaust what they are. So it is because Leibniz is thinking of concepts like king that he says that an accident is something whose concept does not contain everything that is true of the subject to which it applies.

In general, then, one must distinguish between two kinds of concepts of accidents: (a) the concept of an accident $F$ in the sense of being the concept that characterises $F$, and (b) the concept of an accident $F$ in the sense of being the concept that characterises the subjects of $F$ in virtue of those subjects having accident $F$. It should be clear that, in general, a concept of an accident in sense (b) is not a concept of an accident in sense (a), since the concept that characterises the subjects of the accident need not characterise the accident itself. This is what happens in the case of the concepts king and kinghood. ${ }^{26}$

Now, assuming that every entity is the subject of some true predications, Leibniz's idea that the concept of the subject always contains its predicates, ensures that every entity has a complete concept corresponding to sense (a). For take the collection of true predications about a certain entity $X$. In all of them a predicate is attributed to $X$. So the concept of $\mathrm{X}$ must include all those predicates, whether $\mathrm{X}$ is a substance, an accident, or

\footnotetext{
${ }^{26}$ Of course, when the accident is one of its own subjects, like with the accident being an accident, the concept of the accident in sense (b) is also a concept of the accident in sense (a). But this is not the typical case, and it is not the kind of case that Leibniz has in mind in section 8 of the Discourse.
} 
any other entity. In this respect, substances and accidents are on a par: both have complete concepts that completely characterise them. Indeed every entity has a concept that completely characterises it. Thus not only can Leibniz maintain that accidents have complete concepts that include everything that is true of them, he must maintain this.

But accidents do not have complete concepts in sense (b). A complete concept of an accident in sense (b) would completely characterize the subjects of that accident. For instance, if the concept king were complete, it would completely characterize Alexander, and it would therefore contain everything that is true of him. But then either the concept king would not be attributable to Darius or any king other than Alexander, or Alexander would have only the properties that follow from being a king, which means that he would not have been taught by Aristotle, for instance. That concepts of accidents in sense (b) are not complete is what Leibniz means when he says in the Discourse that the notion of an accident does not include everything that can be attributed to the subject to which this notion is attributed. ${ }^{27}$

Thus, although an accident has a complete concept in sense (a), it has an incomplete concept in sense (b). But substances cannot have incomplete concepts in sense (b). For, as we have seen, Leibniz conflated the relations of predication and inherence and he often says that a substance is a subject that is not in another subject, thereby suggesting that a substance is a subject that is or might be its own only subject of inherence. ${ }^{28}$ And, as we shall see in the next section, the idea that a substance is its own subject helps us best understand a passage that is very relevant to our purposes. Taking the possibility that substances are their own subjects of inherence seriously, we can draw the following distinction between concepts of a substance, analogous to the previous distinction between concepts of accidents: (a) the concept of a substance $X$ in the sense of being the concept that characterises $X$, and (b) the concept of a substance $X$ in the sense of being the concept that characterises the subject of $X$ in virtue of its being $X$.

\footnotetext{
${ }^{27}$ Note that even the concept accident, when taken in sense (b), is not complete, since accidents include more than merely being accidents.

${ }^{28}$ A VI.iv: 672, 1506-07.
} 
But since a substance is its own only subject, a complete concept of a substance in sense (a) is a complete concept of that substance in sense (b). For the same reason, a complete concept of a substance in sense (b) is a complete concept of that substance in sense (a). Thus a substance cannot have a complete concept in sense (a) without having a complete concept in sense (b). In short, Leibniz's definition of substance in the Discourse is that of something that has a complete concept in sense (b). ${ }^{29}$

7. Since a substance is its own only subject, in the case of substances concepts in sense (a) and concepts in sense (b) apply to one and the same thing, and in this sense they can be said to coincide. In a note appended to a letter to Arnauld of $14^{\text {th }}$ July of 1686 , Leibniz makes the following distinction between a full and a complete notion or concept: 'A full ('plena') notion contains all the predicates of the thing, for instance of heat; a complete notion contains all the predicates of the subject, for instance of this hot thing. These notions coincide in individual substances' (G.ii.49).

According to this note the full notion completely characterises a 'thing', and the complete notion completely characterises the subject of the 'thing'. This suggests that a full notion is a complete concept in sense (a), whilst a complete notion is a complete concept in sense (b). He then says that in substances full and complete notions coincide, which I take to mean that full and complete notions of substances apply to or characterise the same thing. Since Leibniz uses an accident, namely heat, as an example of what is characterised by a full notion, and the corresponding subject of the accident as an example of what is characterized by a complete notion, the implication of the passage is that the full and complete notions of an accident do not characterise the same thing. The passage also suggests (although, clearly, does not say so explicitly) that accidents do not have complete notions - that is, the passage suggests that, as I have been arguing with

\footnotetext{
${ }^{29}$ Note that if conceived in a more traditional way, as not inhering in any subject, substances do not have incomplete concepts in sense (b). For if substances do not have subjects where they inhere, they do not have concepts in sense (b). Their only concepts are concepts in sense (a) and so they do not have incomplete concepts in sense (b). Thus, whether or not substances are their own subjects, they do not have incomplete concepts in sense (b). If Leibniz had worked with this more traditional conception of substance he should have defined them as things that do not have incomplete concepts in sense (b).
} 
respect to section 8 of the Discourse on Metaphysics, accidents do not have complete concepts in sense (b). Otherwise we would have to attribute to Leibniz the very unLeibnizian view that the concept hot thing includes all the predicates of a certain hot thing.

This note has not passed unnoticed by commentators. Commentating on it, Parkinson says that the difference between full and complete concepts is that full concepts can, but complete concepts cannot, form part of a more complex concept than itself. Indeed for Parkinson a concept is complete if and only if it cannot form part of a concept more complex than itself. ${ }^{30}$ The rationale for this seems to be that the concept of Alexander contains the concept kingship (which I take to be the concept king) but it is not contained in any other more complex concepts. ${ }^{31}$

But Parkinson's account of the distinction between full and complete concepts seems to be incorrect. For Leibniz says that the full concept of heat contains all its predicates. But the predicates of heat are not predicates of hot things. Heat is an accident, hot things are not. So the full concept of heat cannot be part of more complex concepts of hot things. But neither can it be a part of a concept of another accident. For it if it were, heat would be attributable to another accident, and so another accident would be heat. Thus a full notion cannot be part of a more complex concept.

Rutherford correctly says that it is reasonable to suppose that a full notion is to be identified with the kind of concept that is demanded of the subject term of any true proposition by Leibniz's theory of truth. ${ }^{32}$ And then Rutherford accounts for the distinction between full and complete notions in this way: 'A full term contains every term whose predication it entails. However, it places no bounds on there being terms which entail the predication it expresses. By contrast, there can be no term which entails the predication expressed by a complete term, since by definition it contains every term predicable of the same subject' (1988: 141).

\footnotetext{
${ }^{30}$ Parkinson 1965: 127.

${ }^{31}$ Parkinson 1965: 127.

${ }^{32}$ Rutherford 1988: 131.
} 
The way Rutherford characterises full terms or notions does not seem to accord with his idea that full notions are those demanded of the subject term of any true proposition by Leibniz's theory of truth. For Leibniz's theory of truth demands that the subject term of any true proposition has a complete concept that completely characterises it. And so the full notion of heat completely characterises it. Indeed, a full notion is a complete concept in sense (a). The concepts whose terms place no bounds on there being terms which entail the predications they express are concepts of accidents in sense (b). These are incomplete, and so are neither full nor complete. As I have argued, when Leibniz says that an accident does not have a concept that includes everything that is true of the subject to which that concept is attributed, what he means is that the concept of an accident in sense (b) is incomplete. Thus the distinction between full and complete notions is the distinction between complete concepts in sense (a) and complete concepts in sense (b).

8. There are passages where Leibniz explicitly affirms that containing all the predicates of the thing to which a concept is attributed is a sufficient condition for being the concept of a substance. Here is one such text:

If there is a complete notion, namely such that from it a reason can be given for all the predicates of that subject to which this notion can be attributed, it will be a notion of an individual substance, and vice versa. For an individual substance is a subject which is not in any other subject, but in which other things are, and thus all the predicates of the same subject are all the predicates of the same individual substance; of them a reason can be given from the notion of the individual substance, and from it alone.... Thus a notion that does this is certainly a notion of the individual substance itself (A VI.iv: 672). 
This is from a text known as Principium scientiae humanae, ${ }^{33}$ tentatively dated as roughly contemporary to the Discourse. This passage entails that accidents do not have complete concepts in sense (a). For such a complete concept would contain all the predicates of the accident in question. But according to this passage a concept that contains all the predicates of the thing to which it applies is the concept of a substance.

There is also a passage from a text likely to have been written in mid-1685, where Leibniz says that only a singular substance has a complete concept. ${ }^{34}$ And there is also this passage, from On the present world, tentatively dated between the Spring of 1684 and the Winter of 1685-86:

And, in fact, the concept of an individual substance is something complete, which already potentially contains everything whatever can be understood of it. ${ }^{35}$ Thus, God, while conceiving the substance of this Peter, he thereby conceives all things that have happened or will happen to him. Which cannot be said of an individual accident, except insofar as it is conceived to be in an individual substance. From the royal authority of Alphonso I cannot conceive his Astronomy, unless I access the individual nature of Alphonso himself. (...) [A substance] is also unique, because of the fact that its concept is complete, by force of its very essence. But a complete concept is a characteristic ['nota'] of an individual substance (A VI.iv: 1507).

These passages do not permit a distinction between substance and accident. Thus if my interpretation of section 8 of the Discourse on Metaphysics is correct, the Discourse represents an evolution in Leibniz's thought on substance, since he is finally able to give a definition of substance in terms of complete concepts that distinguishes between substance and accident. Although this does not settle the date of the texts presented in this section, it does suggest that they were written before the Discourse on Metaphysics.

\footnotetext{
${ }^{33}$ A VI.iv: 670-2.

${ }^{34}$ A VI.iv: 626.

${ }^{35}$ In this sentence 'it' translates 'ipso', which I believe to be a typo for 'ipsa'. See the next footnote for the Latin text corresponding to this passage: 'Et quidem substantiae singularis conceptus est quiddam completum, qui omnia jam virtute continet, quaecunque de ipso possunt intelligi'.
} 
9. It is important to note that even if Leibniz's definition is able to successfully distinguish between substances and accidents, it might not be able to successfully distinguish between substances and other entities. For instance, consider the property being Alexander. Alexander is Alexander in virtue of having the property being Alexander. So the concept Alexander characterizes Alexander, the subject of the property being Alexander, in virtue of Alexander having that property. Does that concept characterize Alexander completely? It depends on how the property being Alexander is understood. But suppose that from the property being Alexander all the properties of Alexander can be deduced. Then the concept Alexander completely characterizes Alexander, the subject of the property of being Alexander, in virtue of this subject having that property. So this property has a complete concept in sense (b) and so it satisfies the definition of a substance. ${ }^{36}$

But being Alexander is not an accident for Leibniz. For being Alexander is attributable only to Alexander and so it does not satisfy what seems to be the intended nominal definition of an accident, namely that accidents are attributable to more than one subject. Indeed, as Leibniz implies in section 8 , accidents are not sufficiently determinate for one individual. But being Alexander is sufficiently determinate for one individual. Thus being Alexander is not an accident. It is, rather, a particular sort of property, an individual essence or, using the language of the Discourse, a substantial form. And so the problem is that Leibniz's definition of substance does not allow him to distinguish substances from their substantial forms. Whether this is an important problem is itself a delicate problem, but neither is the problem of this paper. ${ }^{37}$

10. I have argued that Leibniz's complete-concept definition of substance in section 8 of the Discourse on Metaphysics allows Leibniz to distinguish between substances and

\footnotetext{
${ }^{36}$ I am indebted to Jeff Snapper for this point.

${ }^{37}$ A similar problem would be in terms of the conjunction of all accidents of Alexander. That collection will have a complete concept in sense (b), since that concept will completely describe Alexander. Again, Leibniz should not consider such a conjunction of accidents as an accident since it is not attributable to more than one subject.
} 
accidents. The key is the merely nominal definition according to which a substance can be predicated of itself and only of itself. What this means is that the concept of a substance is attributed only to the substance in question. Since Leibniz's theory of truth has it that the predicate is always included in the concept of the subject, and the concept of a substance is attributed only to the substance in question, this permits Leibniz to define a substance as having a concept so complete that it includes all the predicates of the subject to which this notion is attributed rather than merely as having a concept so complete that it includes all its predicates. The latter definition would not allow Leibniz to distinguish substances from accidents since accidents also have complete concepts that include all their predicates. But since accidents do not have complete concepts that include all the predicates of the subjects to which they are attributed, Leibniz's actual definition of substance does allow him to distinguish substances from accidents. I used these ideas to elucidate an interesting note where Leibniz distinguishes full and complete concepts or notions and I argued that the definition of substance in the Discourse represents progress in Leibniz's thought on substance in the mid-1680s.

Bibliography

Aristotle. Categories, translated by E. M. Edghill, in Richard McKeon (ed), The Basic Works of Aristotle, New York: The Modern Library, 2001.

Aristotle. Prior Analytics, translated by A. J. Jenkinson, in Richard McKeon (ed), The Basic Works of Aristotle, New York: The Modern Library, 2001.

Aristotle. Metaphysics, translated by W. D. Ross, in Richard McKeon (ed), The Basic Works of Aristotle, New York: The Modern Library, 2001.

Barnes, J. (2003) Porphyry. Introduction, translated with an introduction and commentary by Jonathan Barnes. Oxford: Oxford University Press. 
Broad, C. D. (1972) “Leibniz's Predicate-in-Notion Principle”, in H. G. Frankfurt (ed.) Leibniz. A Collection of Critical Essays, Garden City, N. Y.: Anchor Books, pp. 1-18.

Jolley, N. (2005) Leibniz, London and New York: Routledge.

Joseph, H. W. B. (1949) Lectures on the Philosophy of Leibniz, Oxford: Clarendon Press.

Leibniz, G. W. (1992) Notes on Aloys Temmiks' Philosophia vera theologiae et medicinae ministra, in M. Mugnai Leibniz's Theory of Relations, Stuttgart: Franz Steiner, 1992, pp. 155-60.

Parkinson, G. H. R. (1965) Logic and Reality in Leibniz's Metaphysics, Oxford: Clarendon Press.

Russell, B. (1937) A Critical Exposition of the Philosophy of Leibniz, London: Routledge, $2^{\text {nd }}$ edition.

Rutherford, D. (1988) "Truth, Predication, and the Complete Concept of an Individual", Studia Leibnitiana, Sonderheft 15, Stuttgart: Franz Steiner Verlag, pp. 130-144.

Rutherford, D. (1995) Leibniz and the Rational Order of Nature, Cambridge: Cambridge University Press.

Wilson, C. (1989) Leibniz's Metaphysics: a Historical and Comparative Study, Princeton: Princeton University Press. 